\title{
Socializing Accountability for Improving Primary Healthcare: An Action Research Program in rural Karnataka
}

\author{
Shirin Madon ${ }^{1}$ and S. Krishna ${ }^{2}$ \\ ${ }^{1}$ London School of Economics \& Political Science \\ ${ }^{2} \mathrm{GSM}$ Academy and Indian Institute of Management Bangalore
}

\begin{abstract}
The Alma Ata Declaration of 1978 invoked a socialising form of accountability through which communities and health workers participated in and were jointly accountable for primary healthcare. Aside from a few experiments, by the 1990 s these ideals were quickly replaced by policy prescriptions based on increasing efficiency in data quality and reporting through the introduction of health information systems. More recently, there has been a revival of interest in community participation as a mechanism for improving the poor status of primary healthcare in developing countries through the constitution of village health committees. This paper documents and reflects on nine years of research on interventions aimed at improving primary healthcare accountability in rural Karnataka. Over this period, our focus has shifted from studying how computerised health information systems can strengthen conventional accountability systems to a period of extended participatory action research aimed at socialising accountability practices at village level. The findings from this study constitute vital knowledge for reforming the primary healthcare sector through different policy measures including the design of appropriate technology-based solutions.
\end{abstract}

Keywords: health information systems; socializing accountability; participatory action research; Karnataka

\section{Introduction}

From the time of the Alma Ata Declaration of 1978 with its focus on community participation and inter-sectoral engagement, the issue of improving accountability of primary healthcare has been of key concern. Over the years, however, there have been different ideas about how to achieve this. The Declaration placed much emphasis on decentralising health planning and implementation with the primary health centre (PHC) identified as a new focal local point for coordinating different programmes and for integrating healthcare delivery with other community development priorities such as education and livelihood generation. An important aspect of this approach was its focus on broadening the accountability agenda beyond economic and functional explanations of health agencies to a socialising form of accountability which included informal spaces and local contexts (Lawn et al, 2008). 
The focus on socialising forms of primary healthcare accountability, however, was short-lived. By the early 1990s, influenced by the growing dominance of neoliberal policies amongst donors, attention was placed on achieving cost-effectiveness through performance-based measures. This triggered a wave of studies aimed at measuring improvements in primary healthcare based on targets set for specific programmes under the MDGs1, for example measuring the reduction in maternal mortality rates (Zere et al., 2011). An increasing importance was accorded to the use of data as evidence for improving the way health programmes were implemented However, while computer-based systems produced 'evidence' of efficient usage of funds and supported increased scrutiny of health workers for non-achievement of targets, they did little to improve local planning and analysis of primary healthcare at the community level (Heeks, 2006; Sahay \& Latifov, 2009). More recent efforts made by governments and international development organisations to improve primary healthcare accountability through the deployment of mobile phones to health workers have led to similar conclusions (Madon et al., 2014).

In recent years, there has been a revival of policy interest in community participation through the establishment of health committees at village or ward level in many developing countries such as India, Tanzania, Bangladesh and South Africa (George et al., 2015). Village health committees can be considered part of a wider move to introduce institutionalized or 'invited' spaces for citizens to participate in the monitoring and directing of public service delivery (Cornwall, 2004; Aiyar, 2010). While remaining partially embedded within the institutional apparatus of the state, these spaces have a semi-autonomous existence offering an opportunity for local discretion in the use of government funds and increasing community participation (Madon \& Krishna, forthcoming). This paper focuses on the contribution of practice theories in the ICTD field of study with a specific emphasis on the relevance of participatory action research for studies on primary healthcare in developing countries. Drawing on the experiences we have gained over the past five years in rural Karnataka, we demonstrate how our research trajectory has been directed by the social situation in which our study was embedded which, in turn, has influenced the theories and methods we have adopted.

In the next section we commence by reviewing action research studies in the ICTD field drawing on literature from the health information systems field and extend our discussion to participatory action research in the primary healthcare domain. This is followed by a detailed description of our research trajectory in rural Karnataka first as health information systems researchers and later as participatory action researchers involved in improving village health and community development. Finally, we reflect on the role of practice theories in improving our understanding of the social situation in which ICT interventions are embedded leading with important implications for policy and practice.

\footnotetext{
${ }^{1}$ These are the 8 Millennium Development Goals set by the UN in 2000.
} 


\section{The role of practice theories in improving primary healthcare in developing countries}

While all research ultimately aims to generate knowledge and influence practice, in action research this coupling has been identified to be much closer (Brydon-Miller, 2003). At a philosophical level, scholars discern validity for action research in terms of perceived functionality of the chosen action to produce desirable consequences for an organization as against producing scientific explanation which motivates positivistic science (Sussman \& Evered, 1978). A key value shared by action researchers in a variety of disciplines is the respect for people's knowledge and their ability to understand and address the issues confronting them and their communities using a variety of approaches and methodologies (Elden \& Chisholm, 1993; BrydonMiller, 2003).

In the field of information systems, four broad interrelated premises are recognised as characterizing action research: a prior explication of the purpose of action, practical action in a problem setting, action informing theory, and reason and action to be socially-situated (Baskerville and Myers, 2004). While recognised as useful for ICTD study, relatively few action research studies have been undertaken (Avgerou, 2008). An exception to this are the studies on the HISP system. For example, action research has been used to improve understanding of health systems sustainability with researchers undertaking practical action to trace how local solutions are aligned with larger networks of national-level teams (Braa et al., 2004; Byrne, 2005; Asangansi, 2012). In the field of health policy and planning, there has been a concomitant recognition for moving away from conventional qualitative case studies towards practice-oriented research approaches (Walt et al., 2008; Lehman \& Gilson, 2014).

While action research studies have rendered important insights about health information systems implementation in developing countries, the fourth premise of action research, namely for reason and action to be socially-situated has so far been only partially explored. The focus of studies undertaken to date has been on the formal health planning apparatus and hierarchical systems of accountability typically involving the district health agency reporting to government, rather than on studying, reframing and reconstructing actual social practices through community participation. In an attempt to bridge this gap, in this paper we focus on studying the extent to which the Village Health Sanitation and Nutrition Committees (VHSNCs) established in India in 2008 provide scope for the emergence of an alternative socialising form of accountability to improve the status of primary healthcare which remains poor even in more progressive states like Karnataka with nearly $80 \%$ of the 635 maternal deaths reported in 2015-16 being due to preventable causes such as anaemia (The Hindu, 2016).

By creating a space for participation by local government, political and civil society representatives, village health committees provide a semi-autonomous space for collaborative action and have provided the impetus for our participatory action research (PAR) study. PAR is distinct in that it aims to combine theory and practice in cycles of action and reflection by providing a space in which community partners can come together and critically examine issues they face, generate knowledge and 
take action to address their priorities (Brydon-Miller et al., 2011). Influenced by numerous social struggles and movements particularly in developing countries, PAR has been conceptualised as a participatory and collaborative research approach that aims to carry out more politically-informed and socially-engaged forms of knowledge creation for addressing real world issues (Kemmis \& McTaggart, 2005).

In the context of India's VHSNCs, the authors have been engaged in PAR together with field researchers and community partners in order to critically examine the issues they face and to generate knowledge and take action for improving village health. Following Kemmis \& McTaggart (2005) we identify four key aspects of the social situation to guide our study. First, we are interested in the actual practices that the committee engages in. Second, we would like to understand what knowledge members hold about these practices. Third, of interest to us are the social structures that shape and constrain those practices. Finally, we are interested in the broader discourse within which the daily practices of the VHSNC are becoming institutionalised.

The rest of this paper describes the various activities we undertook as participatory action researchers and how they have contributed to improving our theoretical understanding of primary healthcare accountability.

\section{Participatory action research on village health in Karnataka}

Our first encounter with research on primary healthcare in Karnataka commenced in 2007 with a three-year project funded by the British Council in partnership with the Karuna Trust, a local NGO that had been involved with primary healthcare and community development work in Karnataka for many decades. The aim of the project was to improve primary healthcare accountability by building a computerised data management infrastructure at PHC level that could be used to account for monies spent to higher levels of administration and funding bodies. The study was undertaken in Gumballi PHC managed by the Karuna Trust and through our discussions with agency staff and upon scrutinising the data sets collected at the PHC we found serious concerns related to data quality. For example, monthly reports were routinely incomplete and data presented on similar items under different headings was often found to be inconsistent. This investigation enabled us to improve data management and usage by designing a computerised system to automatically correct for data anomalies as a routine practice although these efforts were directed towards improving conventional upward accountability structures for reporting. During the course of our project, a new policy was launched in India under the auspices of the National Rural Health Mission to introduce Village Health, Sanitation and Nutrition Committees (VHSNCs)2 across the country in order to make primary healthcare more accountable to the community it served. Each committee was mandated to include 15-20 members of the community comprising health workers, school

${ }^{2}$ When established, these committees were called VHSNCs (Village Health and Sanitation Committees). Nutrition was added as an additional aspect of the committees' mandate resulting in the acronym VHSNC from 2014. 
teachers, local politicians, civil society representatives and ordinary members of the community for addressing health, sanitation and nutrition needs of the village and receiving an annual untied grant of Rs. 10,000 (approximately US\$152) from the government. From 2008 until 2010, we observed that in most locations these new village-level structures were only just incipient committees that met infrequently with poor attendance as villagers were unclear about the purpose of the committee (Madon et al., 2010).

From 2011, there was a growing interest among Karuna Trust to investigating how community participation in the VHSNCs would affect primary healthcare. Hence, the participatory action research component of our research on socialising accountability in primary healthcare commenced in earnest in 2011 with a grant from the British Academy to study the VHSNCs in Gumballi PHC and is currently ongoing. Our close involvement with the villages was facilitated by the working relationship we had established earlier with the Karuna Trust NGO. Two observations about the conduct of action research have particularly influenced our approach. First, as proposed by Baskerville and Myers (2004), "social situatedness means that the action researchers must be participant observers". Our team members have assumed the role of participant observers during VHSNC meetings in 12 villages of Gumballi and have facilitated various activities related to improving village health over a period of years. There has been a steady increase in the frequency of meetings and in member attendance which has coincided with the emergence of five key activities, namely raising health awareness, deciding on untied grant usage, self-organisation of the committee, localised village health planning and monitoring, and cross-sector integration (Madon \& Krishna, forthcoming). Over time we have observed three main phases in VHSNC functioning in the villages. The first phase was characterised by the initial identification and enrolment of VHSNC members and by putting in place basic procedures for the conduct of meetings. In the second phase, VHSNC members began to show a more active interest in conducting meetings and in raising awareness about health, sanitation and nutrition practices. This phase was also characterised by a diversification of spending which resulted in noticeable improvements in water cleanliness, sanitation and hygiene in the villages. The third phase represents the current stage of the VHSNCs in Gumballi where regular meetings take place in all the villages and where the five key activities mentioned above have become routinized with a growing confidence amongst members to tackle larger issues such as long-term planning and monitoring in the village, often in conjunction with the gram panchayat 3 and health authorities.

A second observation that has inspired our action research comes from Elden \& Chisholm (1993), "if system self-improvement is a goal, then system members must learn how to make sense of their own data in terms of their own language and in relation to their own perception and values". Over the past four years, the Karuna Trust has supported activities that facilitate this learning experience and in which we have participated as action researchers. We describe these activities below.

\footnotetext{
${ }^{3}$ This is the village council
} 


\subsection{VHSNC capacity-building workshops}

Capacity-building workshops have been an essential part of our action research strategy in Gumballi. These workshops were held between August to October 2014 in each of 15 villages in Gumballi organised by the PHC manager and by ASHA workers4 from each village. Approximately 15-17 VHSNC members attended each workshop.

We invited members to make sense of and share their own understanding of the VHSNCs. Photo 1 illustrates the informal layout of the workshop with members sometimes accompanied by their children. In each village, a member of our team began the workshop with a welcome speech after which the first part of the workshop was devoted to an articulation of village problems by VHSNC members. Members referred to problems related to blocked drains, waste disposal, water sources that needed cleaning, the difficulty of accessing government funds for building an individual household toilet, and the non-receipt of assistance under a government scheme that enables low-income pregnant women to avail of benefits. About onethird of VHSNC members described a major health-related problem to be the lack of cleanliness in the anganwadi centre 5 and school buildings due to garbage disposal and lack of proper toilet facilities. A few villages identified other problems related to damaged roads in the village, irregular clearance of village dustbins and the incidence of malnourished children.

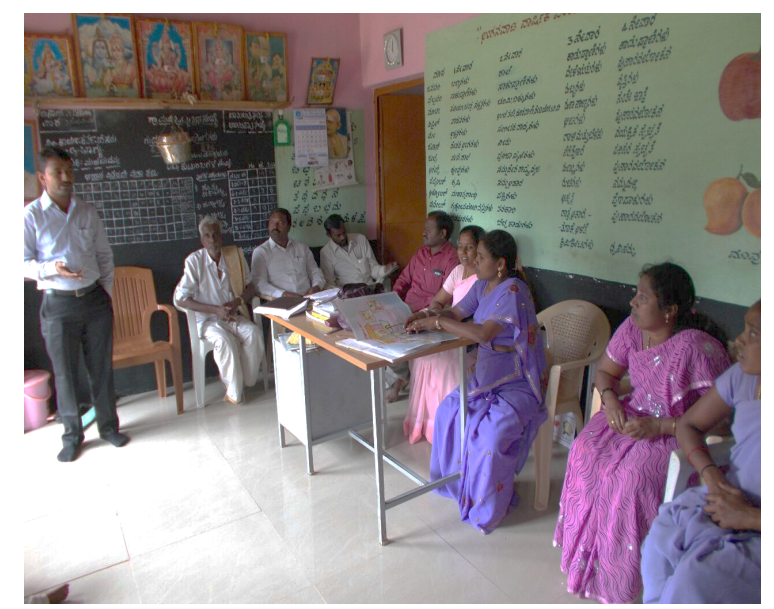

Photo 1. A VHSNC Capacity Building Workshop

\footnotetext{
${ }^{4}$ ASHA stands for Auxiliary Social Health Activist. These workers are local women trained by the health department to act as educators. They serve as an important interface between the community and the health system.

${ }^{5}$ Anganwadi centres offer basic nutrition and health education and well as pre-school activities for the village
} 
In the second part of the workshop we invited members to share with the other workshop participants what they saw as their role in promoting village health. In the majority of villages health workers volunteered for this exercise in which case the female health worker explained that her duties involved providing information about family planning and about government schemes for maternal and child health. In addition, she recognised her duties to involve promoting health and nutrition education, carrying out immunization of communicable diseases and maintaining birth and death register. Male health workers recognised their duties as providing early diagnosis and treatment for communicable diseases such as malaria, TB and leprosy, conducting health surveys, taking water sample from drinking water sources for testing in the PHC laboratory, and providing education in schools. In a small number of cases, the anganwadi worker described her role as treating malnourished children and for imparting education to women and lactating mothers about the importance of regular monitoring of child health as well as maintaining good nutrition and hygiene practices. Similarly, the local school teacher spoke of his responsibility to ensure good sanitation and hygiene within the school and in soliciting the support of the VHSNC in promoting child health.

A third theme in the workshop involved members sharing their ideas about what should be the key priorities for the VHSNC. In almost all villages, members felt that the focus of the committee should be to provide clean drinking water and basic medicines for the PHC, to ensure school children are routinely checked and to identify malnourished children, to create greater awareness of seasonal diseases and to monitor the workload of ASHA and ANM workers as well as provide additional health services. In all villages, VHSNC members found that households were reluctant to build individual toilets despite Government support due to the complexities of actually receiving the grant.

\subsection{Community Monitoring}

The need to involve the community in monitoring health services was expressed during the VHSNC capacity-building workshops and resulted in Karuna Trust working with us to develop a simple format for collecting responses on different aspects of maternal and child health including difficulties faced by health workers in achieving targets. The community monitoring exercise commenced in January 2015 and involved selecting for each village a 6-member team of VHSNC members: President, Secretary, an SC/ST female member, a self-help group member, a youth foundation member, and a villager concerned about maternal and child health. In each village, a member of the community monitoring team asked whether the respondent felt that service delivery was good, average or poor and we further probed the respondent to elaborate on their answer.

The first part of the exercise was about the provision of antenatal, postnatal and new-born care in the village and involved asking ASHA workers about the extent to which they had been able to register antenatal cases, administer tetanus injections for pregnant women, administer IFA tablets, organise institutional delivery, carry out PNC check-up, complete child immunization and prescribe family planning. Figure 2 
provides an example of the format used to tabulate questions and answers collected by the team. One common issue raised by the ASHA worker in all villages was her inability to complete antenatal services because it was customary for pregnant women to relocate to their husband's house after the sixth month of pregnancy. In just under half the villages, the ASHA worker reported she was unable to administer IFA tablets because the stock had run out at the PHC.

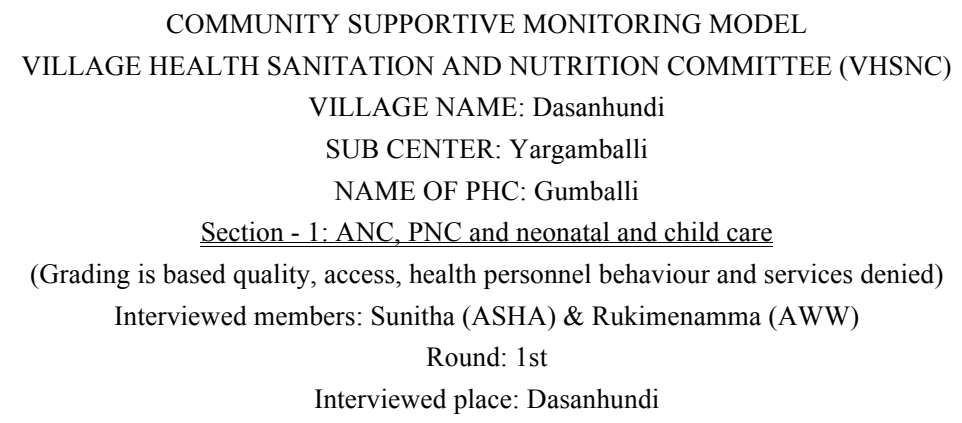

\begin{tabular}{|c|l|c|}
\hline \multirow{2}{*}{ SI.No } & Descriptions & Month \\
\hline 1 & No of registered ANC & Jan-16 \\
\hline 2 & Total no of women received TT & \\
\hline 3 & Total no of women received the IFA & \\
\hline 4 & Women have received the PNC service & \\
\hline 5 & Institutional delivery & \\
\hline 6 & ANC women received 6 times ANC check up & \\
\hline 7 & Children to be immunized during the month & $\begin{array}{l}\text { Number of eligible couples adopted family } \\
\text { planning (Permanent and temporary) }\end{array}$ \\
\hline 8
\end{tabular}

Figure 1. Excerpt from Community Monitoring Format

The second part of the exercise involved asking anganwadi workers6 about how successfully she was able to provide nutrition services such as organising mothers meetings and the statutory Village Health and Nutrition Day, providing supplementary food to antenatal and postnatal women as well as to underweight children, and maintaining cleanliness at the anganwadi centre. In just under half the villages, the anganwadi workers reported that while she had identified malnourished children in the village for support through a government rehabilitation programme,

\footnotetext{
${ }^{6}$ The anganwadi worker is a female worker who specializes in providing basic healthcare and nutrition education to pre-school children under the Integrated Child Development Scheme run by the Ministry of Women and Child Development.
} 
parents were unwilling to send their children as the referral centre was around $20 \mathrm{~km}$. away from the village. In a few cases, the anganwadi worker reported that she was unable to provide food supplements to antenatal and postnatal women during mothers' meetings because of the heavy workload of maintaining 10-12 registers.

The third aspect of the monitoring exercise involved asking VHSNC members about whether the committee was paying importance to ensuring that sanctioned posts were filled, that water sources in the village were periodically tested, that the Immunization Day programme organised every month by the health department was conducted, that adequate benefits were provided to ANC and malnourished children in the village, and that all low-income new mothers had received a free health kit. Responses were generally positive apart from a small number of villages in which antenatal and malnourished beneficiaries had not received benefit from the VHSNC and where water testing had not been carried out.

The final part of the community monitoring exercise was devoted to asking questions to villagers about infant/maternal deaths in the village, deaths due to communicable disease, and whether child marriages took place. In the majority of cases, the responses indicated a low prevalence of deaths although in some villages it was indicated informally that the practice of child marriages was rare but persistent.

\subsection{Village Health Plan}

As referred to earlier, the current stage of VHSNC functioning in Gumballi is characterised by a desire amongst members to tackle larger issues which connect village health with broader community development objectives. In partnership with staff from the Karuna Trust, we commenced the village health plan exercise in September 2015 to address these broader objectives. Three days were spent in each of the villages using participatory rural appraisal tools to involve VHSNC members in drawing maps to identify key resources, the effect of seasons on village life, and income and expenditure patterns in the village.

Using coloured chalk on concrete ground, VHSNC members from each village identified key resources such as drains, toilets, roads and health facilities as illustrated in Photo 2. Often we commenced the exercise of drawing the map as a demonstration which was then continued by 2 or 3 VHSNC members with others contributing to the process. In all villages, members reported that they had access to a $24 / 7$ subcentre, an anganwadi centre and good drinking water facilities. In contrast, the percentage of villages with proper concrete drains ranged from $15-90 \%$ but in all cases the problem of blocked drains was reported as a result of inadequate waste management provision. The percentage of households with individual toilets ranged from $2 \%$ in some villages to $50 \%$ in others signalling that in the majority of cases, villagers practiced open defecation. While in the majority of villages, people had health insurance, in some cases this was less than $30 \%$ of the population. 


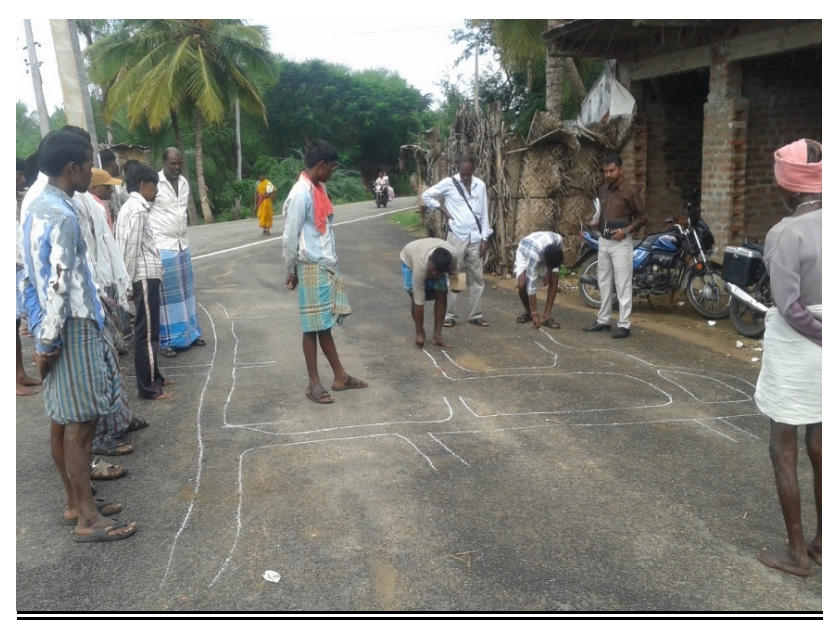

Photo 2. A Village Health Plan Mapping Exercise

The effect of seasons on village life was captured by asking self-help group VHSNC members to draw a calendar on the concrete ground using coloured powder. A good farming season was identified twice a year around April and December which necessitated hard work on farms in the months preceding. Heavy rains were experienced between July and September with fever and cough occurring at the start of the summer season as well as during the rainy season. In all cases, villages held festivals three times a year in January, March/April, September/October and November. The mapping exercise enabled VHSNC members to reflect on the important role of seasonal activities on their health. They identified the need for the VHSNC to plan ahead to promote health awareness before the summer season through home visits, to ensure that testing of water quality and cleaning of drains and that the PHC was well-stocked to supply seasonal medicines.

The final exercise involved VHSNC members drawing a pie chart to show income and expenditure patterns within the village. In the majority of villages, members estimated that approximately $20 \%$ of income was spent on food and nutrition and 20 $30 \%$ was spent on agricultural purposes, for example to purchase seeds, fertilisers, equipment and for labour charges. On the other hand, in all villages, expenditure on festivals was common with the most marginalised of communities spending around $15 \%$ of their income on alcohol and tobacco. The exercise revealed that the rest of household income was spent on a combination of education and for a small amount of saving despite the fact that in all villages women belonged to self-help groups and could access credit. In all villages, the majority of villagers had health insurance but preferred not to spend on health and preferred to use government facilities.

\section{Discussion}

Our research efforts over the past nine years have been dedicated to improving our understanding of how the primary healthcare system in Gumballi PHC, Karnataka can 
be more accountable to the community. Table 1 show a timeline of the different phases of our study. We refer back to the four key aspect of the social situation that have helped frame our study. First, the VHSNCs were established in 2008 based on the assumption that community participation is needed for improving primary healthcare accountability. However, this theoretical premise went unquestioned almost as if the particulars of the practical situation were not important. For example, these committees were not looked upon seriously by higher echelons of the health administration or by PHC medical staff for the first few years of their formation with little interest in understanding how they were functioning. Our focus on the regular routines that take place at village level has presented the opportunity to take seriously these new committees as spaces for socialising accountability in primary healthcare. Acting as PAR in the three support activities promoted by the Karuna Trust has enabled us to gain a deeper insight into the actual lived practices of village health and community development.

Table 1. Timeline showing the trajectory of our study

\begin{tabular}{|l|l|}
\hline \multicolumn{1}{|c|}{ Dates } & \multicolumn{1}{c|}{ Research activity } \\
\hline $2007-2010$ & $\begin{array}{l}\text { Evaluating the impact of health information systems at primary healthcare } \\
\text { level in Karnataka }\end{array}$ \\
\hline 2011 & Participant observation at VHSNCs in Gumballi \\
\hline Aug 2014 & $\begin{array}{l}\text { Participatory Action Research - VHSNC Capacity Building Workshops in } \\
15 \text { villages of Gumballi }\end{array}$ \\
\hline Jan 2015 & Participatory Action Research - Community Monitoring Exercise \\
\hline Sep 2015 & Participatory Action Research - Village Health Plan \\
\hline
\end{tabular}

Second, a wealth of knowledge has accumulated amongst committee members which comes to live in the routine activities that are undertaken within the VHSNCs. For example, members have learnt to use discretion to raise awareness, purchase items members prioritise for maintaining village health, self-organise themselves and network with other village bodies. The three support activities promoted by the Karuna Trust have provided a mechanism for the community to make sense of their own realities in terms of their own language and values. For example, the capacitybuilding workshops enabled key health workers to articulate what they saw as the role of the VHSNC and their own role and responsibilities for maintaining village health. VHSNC members were seen to reflect on village problems to identifying priorities for the VHSNC. The community monitoring exercise provided an opportunity for health workers to account for their own performance in terms of the contingencies they face, for example related to excessive workload and customary practices. Collective development of a village health plan provided the opportunity to elicit knowledge from the VHSNC members about village resources and about how seasonality affected livelihoods, health and income.

Third, PAR has illuminated the enabling and constraining influence of social structures on practice. When the VHSNCs were first established, attendance was poor and meetings were infrequent and it has taken time for these committees to become accepted as part of the social structure within the village, for example in 
terms of gaining support of the village council in the conduct of its activities. Social structures have influenced almost all of the support activities that have been implemented. For example, during the community monitoring exercise, social norms have dictated the movement of pregnant women to their husband's house which in turn have impacted the achievement of antenatal check-up targets for the ASHA worker. Similarly, the social structure of the bureaucracy has resulted in a heavy workload for anganwadi workers to maintain registers thereby preventing them from providing food supplements to antenatal and postnatal women. Finally, social practice of child marriages although only informally reported during our study suggests a constrain for improving village health and promoting community development.

Fourth, there are signs to suggest a transformation of the broader discourse within which village-level practices are being institutionalised. Action on our part has involved several new dimensions that suggest that the VHSNC is gaining more voice. For example, over the past few months we have been asked by VHSNC members to help in the writing of formal complaint letters, for example addressed to the PHC about health workers who underperform. In another case, we were recently asked by VHSNC members to help formulate a letter to be sent to the gram panchayat to complain about the non-repair of water pipes. In August 2016 we held a public dialogue meeting at Gumballi PHC inviting members from VHSNCs and the wider community to raise concerns about any aspect of primary healthcare service delivery. Points highlighted by attendees included an inadequate provision of basic medicines and nutritious food for school children and complaints about non-performing health workers. Proposal were made to hold a regular gynaecological camp for rural women at the PHC, to improve the display of government and PHC services to the community as it was felt that many were unaware about services offered, and to establish a new VHSNC in villages with large populations.

Our action research approach in Gumballi PHC is currently part of a British Academy-sponsored study in which we have worked out an action plan with Karuna Trust for the next two years. During this time, we will continue to conduct PAR in the 15 villages of Gumballi and over the course of the year with further rounds of community monitoring and village health planning and are in the process of identifying emergent village health issues such as the growing prevalence of noncommunicable diseases, psychiatric problems, alcohol and tobacco consumption, and domestic violence in Gumballi. Our research has pointed to the fact that ICT used to gather data through numbers-oriented, centralized and top-down systems to monitor performance of field level workers has been insufficient and problematic in efforts to improve primary health care systems. The action research program we have reported has explored greater local participation through education and participation of community as an essential complement. This naturally leads to the question as to whether ICTs can be used to support more effective functioning of local institutions and organizations in the health care domain. This is indeed possible. Currently health data is aggregated at the PHC level for reports to be considered by higher level bureaucracy. It be would be a simple matter to aggregate at village level and make the information available to VHSNCs for consideration. This simple step, in addition to 
improving awareness of health parameters at the local level, will vastly improve data validity which has been a major concern in the present system in which ANMs have a dual and conflicting role as both caregivers as well as providers of data used to monitor their own performance. Further, the knowledge that is derived at monthly VHSNC meetings can to be systematised and used for improved observation, comparison and learning at higher levels of the health administration. However, the main constraint at least in villages in Karnataka appears to be one of resources. The present VHSNC annual budget of around $\$ 150$ utilized for multiple purposes as discussed earlier cannot, in addition, pay for tablet-based systems and internet connection. At a state level however additional funds to provide such ICT resources are not beyond reach. Hopefully, sustained effective functioning of VHSNCs will persuade state Government to provide required additional resources to move towards next level development of VHSNCs in which they have access to ICT support to help them grow further.

To conclude, one of the broader implications from our paper is that the focus of scholarship on ICTD topics should be not just be on ICTs but on the ' $\mathrm{D}$ ' for development, a point that has repeatedly been raised by scholars in the field (Thompson \& Walsham, 2010; Toyama, 2015). As stated by the founder of Karuna Trust at the start of our action research project, 'only after we have developed a shared understanding of what is involved in improving village health can we think about introducing ICT tools'. As our study has shown, penetrating the complexities of poverty and underdevelopment is a non-trivial exercise in which practice theories can play an indispensable role in improving primary healthcare accountability in resource-poor settings.

\section{References}

Aiyar, Y. (2010) Invited Spaces, Invited Participation: Effects of greater participation on accountability in service delivery, India Review, 9 (2), pp. 204-229.

Asangansi, I. (2012) Understanding HMI Implementation in a Developing Country Ministry of Health Context - An institutional logics perspective, Online Journal of Public Health Informatics, 4, 3, e8.

Avgerou, C. (2008) Information Systems in Developing Countries: A critical research review, Journal of Information Technology, 23, pp. 133-146.

Baskerville R and Myers M.D (2004), "Special Issue on Action Research in Information Systems: Making IS Research Relevant to Practice- Foreword”, MIS Quarterly, 28(3), pp. 329-335.

Braa, J., Monteiro, E. and Sahay, S. (2004) Networks of Action: Sustainable health information systems across developing countries, MIS Quarterly, 28, 3, pp. 337-362.

Brydon-Miller, M., Greenwood, D. and Maguire, P. (2003) Why Action Research? Action Research, 1, 1, pp. 9-28.

Brydon-Miller, M., Kral, M., Maguire, P., Noffke, S. and Sabhlok, A. (2011) Jazz and the Banyan Tree: Roots and riffs on participatory action research. In Handbook of Qualitative Research, edited by K. Denzin \& Y.S. Lincoln, Thousand Oaks: Sage, pp. 387-400.

Byrne, E. (2005) Using Action Research in Information Systems Design to Address Change: A South African health information systems case study, Proceedings SAICSIT '05 
Proceedings of the 2005 Annual Research Conference of the South African Institute of Computer Scientists and Information Technologists on IT Research in Developing Countries, pp. 131-14.

Cornwall, A. (2004) New Democratic Spaces? The politics and dynamics of institutionalised participation, IDS Bulletin, 35, 2, pp. 1-10.

Elden M and Chisholm R F (1993), "Emerging Varieties of Action Research: Introduction to Special Issue", Human Relations, Vol 46(2), pp 121-142

George, A., Scott, K., Garimella, S., Mondal, S., Ved, R. And Sheikh, K. (2015) Anchoring Contextual Analysis in Health Policy and Systems Research: A narrative of contextual factors influencing health committees in low and middle income countries, Social Science \& Medicine, 133, pp. 159-167.

Heeks, R. (2006) Health Information Systems: Failure, success and improvisation, International Journal of Medical Informatics, 75, 2, pp. 125-137.

The Hindu (2016) Primary Health Centres Fail to check Avoidable Maternal Deaths in State, The Hindu, 23 June 2016.

Kemmis, S. and McTaggart, R. (2005) Participatory Action Research: Communicative action and the public sphere. In Handbook of Qualitative Research, edited by K. Denzin \& Y.S. Lincoln, Thousand Oaks: Sage, pp. 556-604.

Lawn, J., Rohde, J., Rifkin, S., Were, M., Paul, V. and Chopra, M. (2008) Alma-Ata 30 Years On: Revolutionary, relevant, and time to revitalize, The Lancet, 372, pp. 917-927.

Lehmann, U. and Gilson, L. (2014) Action Learning for Health System Governance: The reward and challenge of co-production, Health Policy and Planning, 1, 7.

Madon, S. and Krishna, S. (forthcoming) Challenges of Accountability in Resource-Poor Contexts: Lessons about invited spaces from Karnataka's village health committees, Oxford Development Studies.

Madon, S., Krishna, S., Michael, E. (2010) Health Information Systems, Decentralisation and Accountability, Public Administration and Development, 30, 4, pp. 247-260.

Madon, S., Amaguru, J., Malecela, M. and Michael, E. (2014) Can Mobile Phones Help Control Neglected Tropical Diseases: Experiences from Tanzania, Social Science \& Medicine, 102, 103-110.

Sahay, S. and Latifov, M. (2009) The Data to Indicator (Mis)match: Experiences from trying to strengthen this link in the health information system in Tajikistan, Proceedings of the $10^{\text {th }}$ International Conference on Social Implications of Computers in Developing Countries, Dubai School of Government, Dubai, May 2009.

Sussman G. I and Evered R.D (1978) An Assessment of Scientific Merits of Action Research, Administrative Science Quarterly, 23 (4), pp 582-603.

Thompson, M. and Walsham, G. (2010) ICT Research in Africa: Need for a strategic developmental focus, Information Technology for Development, 16, 2, pp. 112-127.

Toyama, K. (2015) Geek Heresy: Rescuing social change from the cult of technology, Public Affairs, New York, NY.

Walsham, G. and Sahay, S. (2006) Research on Information Systems in Developing Countries: Current landscape and future prospects, Information Technology for Development, 12, 1, pp. 7-24.

Walt, G., Shiffman, J., Schneider, H., Murray, S., Brugha, R. and Gilson, L. (2008) 'Doing' Health Policy analysis: Methodological and conceptual reflections and challenges, Health Policy and Planning, 23, pp. 308-317.

Zere, E., Oluwole, D., Kirigia, J., Mwikisa, C. and Mbeeli, T. (2011) Inequities in Skilled Attendance at Birth in Namibia: A decomposition analysis, BMC Pregnancy and Childbirth, 11, 34 . 